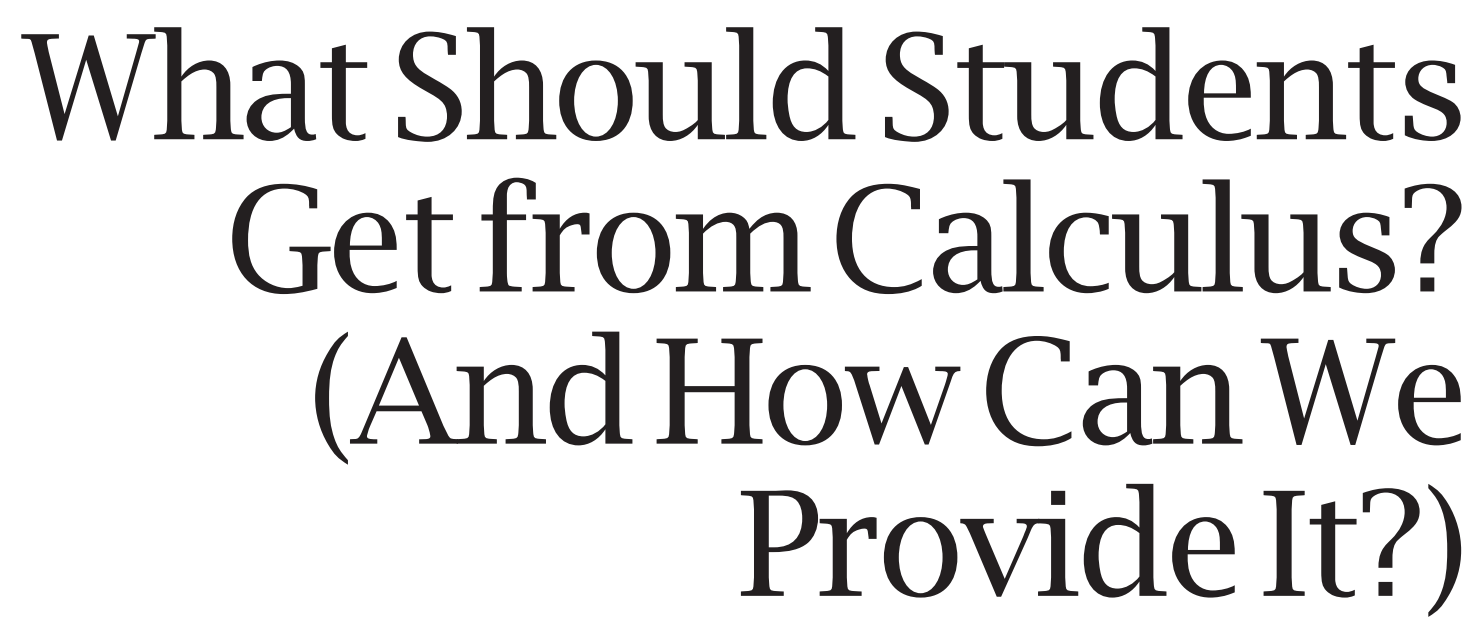

Frank Quinn

In the September 2011 Doceamus column [1], Keith Stroyan takes on this question and reports success with extended exploration of applications. Experiences with a different population of students have led me in rather different directions on practical levels, but with important commonalities.

I back up a bit for perspective. The actual title of Stroyan's article is "Why do so many students take calculus?" The honest answer to this is "because it is required in the curriculum"; the real problem is that traditional calculus courses do not serve students particularly well. Stroyan actually addresses a variation: "We've got them here; what is the best use we can make of this opportunity?" His answer is that calculus gives quick access to rich and varied applications, and he exploits this by reducing emphasis on lectures and the nitty-gritty of calculus and instead exploring applications in some detail. I believe this is a good answer for students who are not in technical programs. Nearly

Frank Quinn is professor of mathematics at Virginia Tech. His email address is quinn@math. vt. edu.

Members of the Editorial Board for Doceamus are: David Bressoud, Roger Howe, Karen King, William McCallum, and Mark Saul.

DOI: http://dx.doi.org/10.1090/noti858 all of my students are in science and engineering, however, so a more mission-oriented version of the question is appropriate. Namely, "What do these students need, and what are the most valuable things they get?" My main concern is with course design. Scientists and engineers do still need a foundation in calculus, but I see calculus as a setting rather than a goal, and even for this group I don't think "knowledge of calculus" is among the most valuable outcomes. The next three sections describe other important goals.

\section{Complex Rules and Accuracy}

It is a vital skill for science and engineering to be able to work accurately with complex, rule-based systems. This skill is also transferrable to many more domains than any specific content. But this is a skill that my students certainly don't have when they get here.

Most high-school programs have de-emphasized rule skills in favor of "understanding" and working intuitively. If you can "see" the problem, it should be easy. Calculator use has replaced a lot of rulebased work and attendant skills. AP calculus is a partial exception, but it is test-driven with greatly simplified rules used mechanically on short, routine problems. Low skill levels give mediocre 
results even on simplified problems, but this has been compensated for by generous partial and extra credit and by curved grades.

Given all this, I feel that helping my students develop disciplined rule skills is the most important service I can provide. An implication for course design-again for students in science and engineering-is that corners should not be cut. Do all the standard techniques of integration, with the full set of elementary functions, to provide enough complexity to require careful and systematic use.

Finally, I think this is the time to get real about getting things right. High-tech employers don't give "A"s for work that is 90\% correct. I expect students to get up to speed, rather than reducing expectations to their comfort zone. Their poor preparation makes this a serious challenge, but an important one, and most of them rise to it.

\section{Abstract and Symbolic Work}

Technical challenges in science and engineering are getting more difficult, while dealing with numbers is getting easier. A consequence is that work on an abstract and symbolic level-even if only to organize numerical work-is increasingly important. But these skills are also declining. Some of my students have trouble with any problem whose answer is not a number: they can handle circles of radius 3 , but simple problems with circles of radius " $r$ " are foreign territory.

Again, I feel my students are better served if I can help develop these skills. My examples and problems usually have symbolic parameters, and I emphasize what these reveal about scaling, optimization, and error analysis. I usually use exact arithmetic. This preserves structure ( $\pi$ and $\sqrt{2}$ don't disappear into decimals) and is halfway to symbolic work. Again this is a challenge, and quite a few students need remediation before it is accessible, but if so they can hardly expect to succeed in a science and engineering curriculum without it.

\section{Applications}

Applications provide opportunities for students to exercise their skills and see the methods in action. However, applications do not have to be physical problems, and in fact I find most physical applications unsatisfactory.

- It is a good idea to plug in numbers from time to time, but it destroys a lot of functionality and does not exercise the most important skills.

- Most of these students have specific interests. Applications that address their interests will be done in more depth in other courses. Applications that don't address their interests often don't engage them.
- Superficial applications are usually little more than vocabulary (replace "velocity" with the first derivative, etc.). These are worth mentioning, but as testable material they are not a good use of their time.

On the other hand, working a bit more abstractly and symbolically opens up mathematical topics to explore. These are, in effect, applications that are both mission-related and quickly accessible because techniques and terminology are already in place.

\section{Resource Constraints}

Unfortunately, one more version of the title question must be addressed: "If we do figure out what students need, can we afford to provide it?" I individually, and my department at Virginia Tech collectively, have tried many things that improved learning but had to be abandoned because they required unsustainable levels of faculty overtime. These include group projects along the lines described in [1]. My suggestions here are also problematic. They don't directly cost more, but increasing expectations increases failure rates unless individual help is provided, and appropriate help would definitely be over-budget.

We should remember that per-student resource levels were established at a time when we only lectured and gave tests. In many colleges they have declined substantially below this level, and huge classes taught by adjuncts are increasingly common. In this climate any innovation that costs more is a dead end. Real impact in first- and second-year courses will require innovations whose resource requirements are competitive with huge classes taught by adjuncts. So far, an educational approach to innovation has been taken: "discipline stifles creativity, so let a thousand flowers bloom." Unsurprisingly, we have reaped education-quality outcomes: the thousand flowers bloomed and wilted, and very few students are better off. Maybe it is time to get real about getting it right, perhaps with a science and engineering approach: "no discipline, no results."

The sticking point is that, as far as I can see, the only way to both innovate and reduce costs is to give up traditional classrooms. Nothing else has enough value. This could work, though: at Virginia Tech we now have more than 10,000 students per semester taking lower-level computer-based courses. Unit costs are enough below the hugeclass-with-adjuncts cutoff that Stroyan's group projects, or the individual help that I feel is so important, could be done within current budgets. There is still a big challenge: developing highquality courseware and tests that would provide a good environment for these other innovations. Most courseware follows the classroom model, 
and it really should be clear by now that this is a poor model. We need materials much better adapted to individual use. Real success will also require sophisticated adjustments in the content. My belief is that this is a job for mathematicians, not educators. ${ }^{1}$

\section{Summary}

Stroyan suggests a kinder, gentler calculus with extended projects on physical applications. I propose a more rigorous course with fewer physical applications. How can I see these as basically similar?

Both of us are concerned that traditional calculus courses do not serve students particularly well. We both feel-for rather different reasons-that calculus is a good setting and that the real problem is the traditional format. In particular, calculus is not the main learning goal even in a calculus course. We both believe that better goals should reflect student needs; the differences in specific approaches reflect different student populations. We have both concluded that serving students well will require activity—again different in detail—outside traditional classroom settings.

A final similarity is that wide implementation of either approach is seriously limited by resource constraints. They might be seen as examples of enrichments and student-specific variations that would be possible with high-quality computerbased courses.

\section{References}

[1] KeITH Stroyan, Doceamus: Why do so many students take calculus?, Notices Amer. Math. Soc. 58 (2011), no. 8, 1122-1123.

${ }_{1}^{1}$ See the essays at http://www. math.vt.edu/people/ quinn/education/for extensive discussion of these issues.

\section{SCRIPTA MANENT \\ ...written words endure}

\section{Shifting Editorial Boards}

Susan Hezlet

With the launch of the Elsevier boycott, the example of the new Journal of Topology has come up several times. Some scientists are proposing that other journal boards resign and move to new publishers. It is not that simple. In recent years the London Mathematical Society (LMS) has taken on three journal projects whose different stories illustrate the problems along with the benefits

Susan Hezlet is the publisher at the London Mathematical Society. Her email address is hez 1 et@1ms . ac.uk.

Members of the Editorial Board for "Scripta Manent" are: Jon Borwein, Thierry Bouche, John Ewing, Andrew Odlyzko, and Ann Okerson.

DOI: http://dx.doi.org/10.1090/noti856 to be gained if you get it right. What follows is a personal account of the journal moves.

\section{Case 1. Compositio Mathematica}

The journal, founded by Brouwer in the 1930s, is owned by a Dutch foundation, Compositio Mathematica. It was published for many years by Kluwer (now a part of Springer), but in reaction to increasingly higher prices, the foundation looked for an alternative cooperation with a learned society, and agreement was reached with the LMS. The LMS negotiated a separate agreement with Cambridge University Press that they would print, host online, and sell the journal.

Kluwer did not own the journal and handed over the subscription data along with archives for 